\title{
THE SCORING AND INTERPRETATION OF THE SDQ-20 AND SDQ-5
}

\author{
Ellert R.S. Nijenhuis" \\ Mental Health Care Drenthe Outpatient Department, Assen, The Netherlands \\ Received November 12, 2010; accepted November 21, 2010
}

\begin{abstract}
The 20-item Somatoform Dissociation Questionnaire (SDQ-20; Nijenhuis, Spinhoven, Van Dyck, Van der Hart, \& Vanderlinden, 1996) evaluates the severity of somatoform dissociation. The SDQ-20 items were derived from a pool of 75 items describing clinically observed somatoform dissociative symptoms that in clinical settings had appeared upon reactivation of particular dissociative parts of the personality and that could not be medically explained. The SDQ-20 scores were best predicted by self-reported physical and sexual traumatization in patients with dissociative disorders and psychiatric controls (Nijenhuis et al., 1998c), even after statistically controlling for self-reported emotional traumatization (emotional neglect and emotional abuse). These traumatization scores were composed of four factors, i.e. presence of trauma, duration of trauma, relationship to perpetrator, and subjectively rated impact of trauma.
\end{abstract}

Key words: Dissociation; Somatoform dissociation; Somatoform Dissociation Questionnaire; Reliability; Validity

\section{INTRODUCTION}

The 20-item Somatoform Dissociation Questionnaire (SDQ-20; Nijenhuis, Spinhoven, Van Dyck, Van der Hart, \& Vanderlinden, 1996) evaluates the severity of somatoform dissociation. The SDQ-20 items were derived from a pool of 75 items describing clinically observed somatoform dissociative symptoms that in clinical settings had appeared upon reactivation of particular dissociative parts of the personality and that could not be medically explained. The items pertain to negative (e.g., analgesia) and positive dissociative phenomena (e.g., site-specific pain).

\section{SCORING}

The items are supplied with a Likert-type 5-point scale, ranging from " $1=$ this applies to me NOT AT ALL" to "5 = this applies to me EXTREMELY."

The respondent is also asked to indicate whether a physician has connected the symptom or bodily experience with a physical disease. In our SDQ-studies, we have not adjusted the item scores when physical disease was indicated, as such indications often did not seem to be accurate. For example, the respondent might interpret "hyperventilation" as a physical disease. We therefore suggest that the item scores are not adjusted for indicated physical disease when the SDQ-20 (or SDQ-5) is used for research purposes. However, in clinical practice one may wish to adjust the relevant item score to "1" when physical disease is indicated, the medical diagnosis has been checked with the physician who assigned it, and this diagnosis seems valid. The SDQ-20 score, which may range from 20 to 100 , is obtained by summation of the individual item scores.

The psychometric characteristics of the SDQ-20 were explored in several studies (France: El-Hage, DarvesBornoz, Allilaire, \& Gaillard, 2002; The Netherlands/Belgium: Nijenhuis et al., 1996, 1997b, 1998b, 1998c, 1999; Turkey: Sar, Kundakci, Kiziltan, Bakim, \& Bozkurt, 2000). The results of these studies demonstrated that the scalability, reliability, and validity of the instrument are very satisfactory.

\section{SCALABILITY}

Mokken scale analysis showed that the 20 items are strongly scalable (Nijenhuis et al., 1996: Loevinger coefficient of homogeneity $\mathrm{H}=.50$; Nijenhuis et al., 1998b: 0.56). The items met the assumptions of single and double monotonicity. In a replication study

*Correspondence to: Ellert Nijenhuis, email: e.nijenhuis@home.nl 
(Nijenhuis et al., 1998b), one item (Mokken coefficient of homogeneity $=0.28$ ) failed to reach the lowerbound (0.30), but its exclusion only marginally affected the Loevinger coefficient of homogeneity (increasing to 0.58). The Mokken coefficients of homogeneity of the other items ranged from 0.40 to 0.63 .

\section{RELIABILITY}

The internal consistency of the SDQ-20 is excellent (Nijenhuis et al., 1996, Cronbach's alpha 0.95; Nijenhuis et al., 1998b: .96). The test-retest reliability is very satisfactory (Sar et al., 2000).

\section{RELATIONSHIP WITH DEMOGRAPHIC CHARACTERISTICS}

We have not found indications that SDQ-20 scores are affected by age or gender.

\section{CONVERGENT VALIDITY}

As we found (Nijenhuis et al., 1996), the intercorrelations between the SDQ-20 score and the DIS-Q total score as well as three of the four factor scores were high $(.71<\mathrm{r}<.76, \mathrm{p}<.0001)$. The intercorrelation with the absorption scale was more moderate $(r=.46, p<.0001)$. In a replication study (Nijenhuis et al., 1998b), the intercorrelation between the SDQ 20 and the DIS Q total score was $\mathrm{r}=.82$, and the correlations between the SDQ and the four DIS-Q factor scores were as follows: identity fragmentation factor $\mathrm{r}=.81$; loss of control, $\mathrm{r}=.72$; amnesia, $\mathrm{r}=.80$; absorption $\mathrm{r}=.60$.

In yet another study (Nijenhuis et al., 1997b), an intercorrelation of $\mathrm{r}=.85$ with the Dissociative Experiences Scale (DES, Bernstein \& Putnam, 1986) was assessed. Nijenhuis, Van der Hart, and Kruger (2002) and Sar et al. (2000) also found a strong association between the SDQ-20 and the DES in psychiatric patients, Nijenhuis and Van Duyl (2001) in Ugandan patients with spirit possession disorder, and Nijenhuis et al. (2003) in women with chronic pelvic pain.

These results strongly support the convergent validity of the SDQ-20.

\section{DISCRIMINANT VALIDITY}

The SDQ-20 discriminates between (i) Dissociative Identity Disorder, (ii) Dissociative Disorder NOS, (iii) Somatoform Disorders, and (iv) other psychiatric diagnostic categories, including bipolar mood disorder.

Sar et al. (2000) also found that somatoform dissociation was extreme in DSM-IV dissociative disorders, quite modest in anxiety disorders, major depression, and schizophrenia, and low in bipolar mood disorder. ElHage et al. (2002) documented that patients with PTSD had higher SDQ-20 scores than psychiatric patients without PTSD or dissociative disorders. Patients with pseudo-epileptic seizures have higher SDQ-20 scores than in patients with temporal lobe epilepsy (Kuyk,
Spinhoven, Van Emde Boas, \& Van Dyck, 1999), and Ugandan patients with spirit possession disorder have higher SDQ-20 scores, compared to mentally healthy controls (Nijenhuis \& Van Duyl, 2001). Waller, et al. (2003) documented somatoform dissociation in patients with bulimia.

Table 1. SDQ-20 scores for different diagnostic categories

\begin{tabular}{|c|c|c|c|}
\hline Nijenhuis et al.: & $1998 \mathrm{a}$ & 1999 & Sar et al., 2000 \\
\hline & $\begin{array}{llll}M & S D & M & S D\end{array}$ & $M S D$ & $M \quad S D$ \\
\hline DID & $51.812 .6 \quad 57.314 .9$ & 55.113 .5 & $58.7 \quad 17.9$ \\
\hline DDNOS & $43.8 \quad 7.11 \quad 44.611 .9$ & $43.0 \quad 12.0$ & 46.316 .2 \\
\hline Somatoform disorders & & $32.0 \quad 9.6$ & \\
\hline Eating disorders & & $27.7 \quad 8.8$ & \\
\hline Schizophremia & & & 27.19 .5 \\
\hline \multicolumn{4}{|l|}{ Mixed non-dissociative psychiatric } \\
\hline \multicolumn{4}{|l|}{ patients (mainly anxiety disorders, } \\
\hline depression, adjus(ment disorders) & 23.53 .97 & $22.9 \quad 3.9$ & \\
\hline Anxiety disorder & & & 26.86 .4 \\
\hline Major depressive episode & & & 28.78 .3 \\
\hline Bipolar mood disorder & & $21.6 \quad 1.9$ & 22.73 .5 \\
\hline Non clinical probands & & & 27.48 .2 \\
\hline
\end{tabular}

The above differences between (i) DID, (ii) DDNOS, (iii) somatoform disorders, and (iv) other psychiatric disorders remained statistically significant after controlling for general psychopathology as assessed with the SCL-90-R (Derogatis, 1986; Nijenhuis et al., 1999). Somatoform dissociation thus differs from general psychopathology.

\section{CONSTRUCT VALIDITY}

The SDQ-20 scores were best predicted by self-reported physical and sexual traumatization in patients with dissociative disorders and psychiatric controls (Nijenhuis et al., 1998c), even after statistically controlling for self reported emotional traumatization (emotional neglect and emotional abuse). These traumatization scores were composed of four factors, i.e. presence of trauma, duration of trauma, relationship to perpetrator, and subjectively rated impact of trauma. Self-reported traumatization in the developmental period $0-6$ years predicted somatoform dissociation best.

Somatoform dissociation was strongly associated with reported exposure to potentially traumatizing events, notably cumulative trauma reporting and bodily threat from a person in a range of other studies, even after statistically controlling for self reported emotional neglect and emotional abuse (Nijenhuis et al., 1998c; Nijenhuis, Van Engen, Kusters, \& Van der Hart, 2001; Nijenhuis et al., 2003; Nijenhuis, Van der Hart, Steele, \& Kruger, 2004; Nijenhuis \& Van Duyl, 2001; Waller et al., 2000). Physical abuse was associated with more somatoform dissociative symptoms in patients with 
DSM-IV conversion disorder, described in ICD-10 as dissociative disorders of movement and sensation (Roelofs, Keijsers, Hoogduin, Naring, \& Moene, 2002). Conjointly, these studies demonstrate consistent associations between somatoform dissociation and reported cumulative traumatization and threat from a person to the integrity of the body and life in clinical and nonclinical samples, and in samples from different cultures.

\section{SOMATOFORM DISSOCIATION AND SUGGESTION}

Some authors claim that dissociation scores result from suggestion. For example, Merskey $(1992,1997)$ maintains that dissociative disorder patients are extremely suggestible, and therefore vulnerable to indoctrination by therapists who mistake the symptoms of bipolar mood disorder for "dissociative" symptoms. However, there are noteworthy reasons to believe that suggestion and indoctrination do not explain somatoform dissociation. Patients who completed the SDQ-20 in the assessment phase, and prior to the SCID-D interview, had higher scores than dissociative patients who completed the instrument in the course of their therapy (Nijenhuis et al., 1997a; Nijenhuis, Van Dyck, Van der Hart, \& Spinhoven, 1998d; Nijenhuis, Van Dyck et al., 1999b). Moreover, prior to our research, the symptoms described by SDQ-20 were not known as major symptoms of dissociative disorders among diagnosticians and therapist, let alone patients. It was also found that the dissociative patients who were in treatment with the present author did not exceed the SDQ-20 scores of dissociative patients who were treated by other therapists. Given this author's theoretical orientation and expectations, he was the most likely person to suggest somatoform dissociative symptoms (Nijenhuis, Spinhoven, Vanderlinden, Van Dyck, \& Van der Hart, 1998a). Hence, the available empirical data run contrary to the hypothesis that somatoform dissociation results from suggestion.

\section{SDQ-5}

The 5-item SDQ-5 was derived from the SDQ-20, and includes the items $4,8,13,15$, and 18 . The 5 -items as a group discriminated best between patients with dissociative disorders and non-dissociative psychiatric comparison patients (Nijenhuis et al., 1997b, 1998b). The scores range from 5 to 25 .

Sensitivity and specificity were high, positive predictive value corrected for prevalence of dissociative disorders, rated at $10 \%$ among psychiatric patients, was satisfactory, and prevalence-corrected negative predictive value was excellent. Studying three independent samples we found that a score of $\geq 8$ yielded the optimal balance between sensitivity and specificity. Among all patients of these samples, only one patient who did not have dissociative disorder obtained a score $\geq 11$.
Compared with the DES as a screening instrument for dissociative disorder (Draijer \& Boon, 1993), the SDQ5 did at least equally well.

According to the results of three samples we studied, $43 \%-84 \%$ of the respondents who obtain a score of $\geq 8$ would have dissociative disorder. When one would assume that the prevalence of dissociative disorders among psychiatric outpatients is $5 \%$, one in two patients with above cut-off scores would have one of the DSMIV dissociative disorders.

Table 2. Sensitivity, specificity, as well as prevalenceadjusted positive and negative predictive value at the optimal cut-off value

\begin{tabular}{|llll|}
\hline Cut-off $\geq 8$ & Nijenhuis et al. & Nijenhuis et al. & Nijenhuis et al. \\
\hline & 1997 & 1997 & $1998 \mathrm{a}$ \\
\hline & Sample I & Sample II & \\
\hline Sensitivity & $94 \%$ & $82 \%$ & $94 \%$ \\
\hline Specificity & $96 \%$ & $88 \%$ & $98 \%$ \\
\hline & & & \\
\hline Positive predictive value & & & $84 \%$ \\
\hline adjusted for prevalence & $72 \%$ & $43 \%$ & \\
\hline & & & $99 \%$ \\
\hline Negative predictive value & & $98 \%$ & \\
\hline adjusted for prevalence & $99 \%$ &
\end{tabular}

The SDQ-5 was more sensitive than the DES to assess dissociative pathology among patients with somatoform disorders. About two thirds of them passed the SDQ-5 cut-off, while a quarter passed the DES cut-off. Many somatoform disorder patients thus seem to experience substantial somatoform dissociation, while a minority experiences considerable psychological dissociation.

A third of the 50 eating disorder patients we studied obtained above cut-off SDQ-5 scores. None of the bipolar mood disorder patients passed this value, as did very few of a mixed comparison group which mainly included anxiety disorders, depression, and adjustment disorder.

Patients who obtain SDQ-5 scores $\geq 8$ should be interviewed using the SCID-D (Steinberg et al., 1993) or DDIS (Ross et al., 1990) in order to assess or exclude dissociative disorder.

The SDQ-5 performed less well in a sample of Turkish psychiatric patients (Sar et al., 2000). In this sample, the sensitivity and specificity of the SDQ-20 were more satisfactory. At the optimal cut-off of 35 , and corrected for a prevalence of dissociative disorders estimated at $10 \%$, the sensitivity was 0.45 , and the specificity 0.98 . The sensitivity and specificity of the DES at a cut-off of 25 were very similar. In Dutch/Flamish samples, the discriminating power of the SDQ-20 was slightly less, compared to this power of the SDQ-5 (Nijenhuis et al., 1997b). 


\section{REFERENCES}

Bernstein, E., \& Putnam, F. (1986). Development, reliability, and validity of a dissociation scale. Journal of Nervous and Mental Disease, 102,280 286.

Draijer, N., \& Boon, S. (1993). The validation of the Dissociative Experiences Scale against the criterion of the SCID D, using receiver operating characteristics (ROC) analysis. Dissociation, 6, 2838.

El-Hage, W., Darves-Bornoz, J.-M., Allilaire, J.-F., \& Gaillard, P. (2002). Posttraumatic somatoform dissociation in French psychiatric outpatients. Journal of Trauma and Dissociation, 3, 3, 59-73.

Kuyk, J., Spinhoven, P., Van Emde Boas, W., \& Van Dyck, R. (1999). Dissociation in temporal lobe epilepsy and pseudo-epileptic seizure patients. Journal of Nervous and Mental Disease, 187, 12, 713-720.

Merskey, H. (1992). The manufacture of personalities: The production of multiple personality disorder. British Journal of Psychiatry, 160, 327340.

Merskey, H. (1997). Tests of "dissociation" and mood disorder (letter), British Journal of Psychiatry, 171, 487.

Nijenhuis, E.R.S., Spinhoven, P., Vanderlinden, J., Van Dyck, R., \& Van der Hart, O. (1998a). Somatoform dissociative symptoms as related to animal defensive reactions to predatory threat and injury. Journal of $A b$ normal Psychology, 107, 63-73.

Nijenhuis, E.R.S., Spinhoven, P., Van Dyck, R., Van der Hart, O., De Graaf, A.M.J., \& Knoppert, E.A.M. (1997a). Dissociative pathology discriminates between bipolar mood disorder and dissociative disorder. British Journal of Psychiatry, 170, 581.

Nijenhuis, E.R.S., Spinhoven, P., Van Dyck, R., Van der Hart, O., \& Vanderlinden, J. (1996). The development and the psychometric characteristics of the Somatoform Dissociation Questionnaire (SDQ 20). Journal of Nervous and Mental Disease, 184, 688694.

Nijenhuis, E.R.S., Spinhoven, P., Van Dyck, R., Van der Hart, O., Chatrou, M., Moene, F. \& Vanderlinden, J. (1999). Somatoform dissociation discriminates among diagnostic groups over and above general psychopathology. Australian and New Zealand Journal of Psychiatry, 33, 512-520.

Nijenhuis, E.R.S., Spinhoven, P., Van Dyck, R., Van der Hart, O., \& Vanderlinden, J. (1997b). The development of the Somatoform Dissociation Questionnaire (SDQ 5) as a screening instrument for dissociative disorders. Acta Psychiatrica Scandinavica, 96, 311-318.

Nijenhuis, E.R.S., Spinhoven, P., Van Dyck, R., Van der Hart, O., \& Vanderlinden, J. (1998b). Psychometric characteristics of the Somatoform Dissociation Ques- tionnaire: A replication study. Psychotherapy \& Psychosomatics, 67, 17-23.

Nijenhuis, E.R.S., Spinhoven, P., Van Dyck, R., Van der Hart, O., \& Vanderlinden, J. (1998c). Degree of somatoform and psychological dissociation in dissociative disorder is correlated with reported trauma. Journal of Traumatic Stress, 11, 711-730.

Nijenhuis, E.R.S., Van der Hart, O., \& Kruger, K. (2002). The psychometric characteristics of the Traumatic Experiences Questionnaire (TEC): First findings among psychiatric outpatients. Clinical Psychology and Psychotherapy, 9(3), 200-210.

Nijenhuis, E.R.S., Van der Hart, O., Kruger, K. \& Steele, K. (2004). Somatoform dissociation, reported trauma, and animal defence-like reactions. Australian and New Zealand Journal of Psychiatry, 38, 678 - 686.

Nijenhuis, E.R.S. \& Van Duyl, M. (2001). Dissociative symptoms and reported trauma among Ugandan patients with possessive trance disorder. Proceedings of the 18th International Fall Conference of the International Society for the Study of Dissociation. New Orleans, December 2-4.

Nijenhuis, E.R.S., Van Dyck, R., Ter Kuile, M.M., Mourits, M.J.E., Spinhoven, P., \& Van der Hart, O. (2003). Evidence for associations among somatoform dissociation, psychological dissociation and reported trauma in patients with chronic pelvic pain. Journal of Psychosomatic Obstetrics and Gynecology, 24, 87-98.

Nijenhuis, E.R.S., Van Dyck, R., Van der Hart, O., \& Spinhoven, P. (1998d). Somatoform dissociation is unlikely to be a result of indoctrination by therapists (letter). British Journal of Psychiatry, 172, 452.

Nijenhuis, E.R.S., Van Engen, A., Kusters, I., \& Van der Hart, O. (2001). Peritraumatic somatoform and psychological dissociation in relation to recall of childhood sexual abuse. Journal of Trauma and Dissociation, 2, 49-68.

Roelofs, K., Keijsers, G.P., Hoogduin, K.A., Naring, G.W., \& Moene, F.C. (2002). Childhood abuse in patients with conversion disorder. American Journal of Psychiatry, 159, 1908-1913.

Ross, C.A., Heber, S., \& Anderson, G. (1990). The dissociative disorders interview

schedule. American Journal of Psychiatry, 147, 1698 1699.

Sar, V., Kundakci, T., Kiziltan, E., Bakim, B., Bozkurt, O. (2000). Differentiating dissociative disorders from other diagnostic groups through somatoform dissociation in Turkey. Journal of Trauma and Dissociation, 1, 67-80.

Steinberg, M., Cichetti, D.V., Buchanan, J., Hall, P., \& Rounsaville, B. (1993). Clinical assessment of dissociative symptoms and disorders: The Structured Clinical Interview for DSM IV Dissociative Disorders. Dissociation, 6, 3-16. 
Waller, G., Babbs, M., Wright, F., Potterton, C., Meyer, C., \& Leung, N. (2003). Somatoform dissociation in eating-disordered patients. Behavior, Research, \& Therapy, 41, 619-627.

Waller, G., Hamilton, K., Elliott, P., Lewendon, J., Stopa, L., Waters, A., Kennedy, F., Lee, G., Pearson, D., Kennerley, H., Hargreaves, I., Bashford, V., \& Chalkey, J. (2000). Somatoform dissociation, psychological dissociation and specific forms of trauma. Journal of Trauma and Dissociation, 1, 81-98.

The SDQ-20 should be referred to as: Nijenhuis, Spinhoven, Van Dyck, Van der Hart, \& Vanderlinden (1996).

The SDQ-5 should be referred to as: Nijenhuis, Spinhoven, Van Dyck, Van der Hart, \& Vanderlinden (1997). 